\title{
Cytomorphological Studies in Two Autotriploids of Capsicum annuum $\mathrm{L}$.
}

\author{
N. Lakshmi and V.R. Polagani \\ Department of Botany, Nagarjuna University, Nagarjunanagar, \\ Guntur District, A. P., India
}

Accepted July 8, 1986

Production of polyploids is of immense value in plant breeding since they are considered to be one of the sources of variation and thus helps in evolution. Both induced and naturally occurring triploids were recorded earlier in Capsicum. (Pal and Ramanujam 1939, Kormos 1954, Chennaveeraiah and Habit 1973, Nishiyama and Karasawa 1954, Ohta 1962). The present investigation pertains to cytomorphological study of the two autotriploids obtained for the first time in the progeny of intraspecific hybrids of a male sterile line with two varieties of Capsicum annuum $\mathrm{L}$.

\section{Materials and methods}

Two triploids isolated in the $F_{1}$ hybrid progeny of Male sterile $\times$ Cluster (Triploid-1) and Male sterile $\times$ Santaka (Triploid-2) respectively constituted the material of the present investigation. For meiotic studies young flower buds were fixed in 1:3 acetic alcohol mixture. After 24 hours the material was transferred to $70 \%$ alcohol and stored in a refrigerator. Acetocarmine squash technique was employed for making meiotic preparations. Pollen fertility was estimated by using $4 \%$ iodine-potassium iodide solution. Densely filled and darkly stained, round pollen grains were considered as fertile and lightly stained. shrivelled as sterile.

\section{Observations}

a. Morphology: Morphometrics of the triploids, sibling hybrids and their parents are given in Table 1. Both the triploids were highly vigorous and taller with good spread than the sibling hybrids and their parents (Figs. 1,2). However, there was no significant change in leaf and flower size. Fruit and seed number as well as their size were remarkably reduced. Pollen fertility was also highly reduced (Table 1).

b. Meiosis: Cytological analysis revealed the triploid chromosome number of $2 n=36$ (Fig. 5). The meiotic behaviour of these two, exhibited differences in the frequency of chromosome associations (Table 2), average number of chiasmata, univalents, segregation of chromosomes at anaphase I and pollen fertility. In Triploid-1, the maximum chromosome association was a quadrivalent, while in the second triploid, an association of six chromosomes was observed (Fig. 5). The most frequently encountered association in both was a trivalent (Table 2, Figs. 5, 6), the number of which varied from 3-6 in Triploid-1 and 3-7 in Triploid-2 per cell. Bivalents were observed 6.77 per cell in Triploid-1 and 6.36 in Triploid-2. Univalents were present in both (Figs. 5, 6) 3-13 in Triploid-1 with a mean of 7.93, and 4-11 in Triploid-2 with a mean of 7.86 per cell. Average number of chiasmata per cell was 21.83 and 20.44 respectively.

Anaphase I was highly irregular in the two triploids with a number of lagging chromosomes (2-11) (Table 3). A maximum of 11 chromosomes were found to be lagging which organize into different groups as a consequence of which telophase II was also highly abnormal with the 


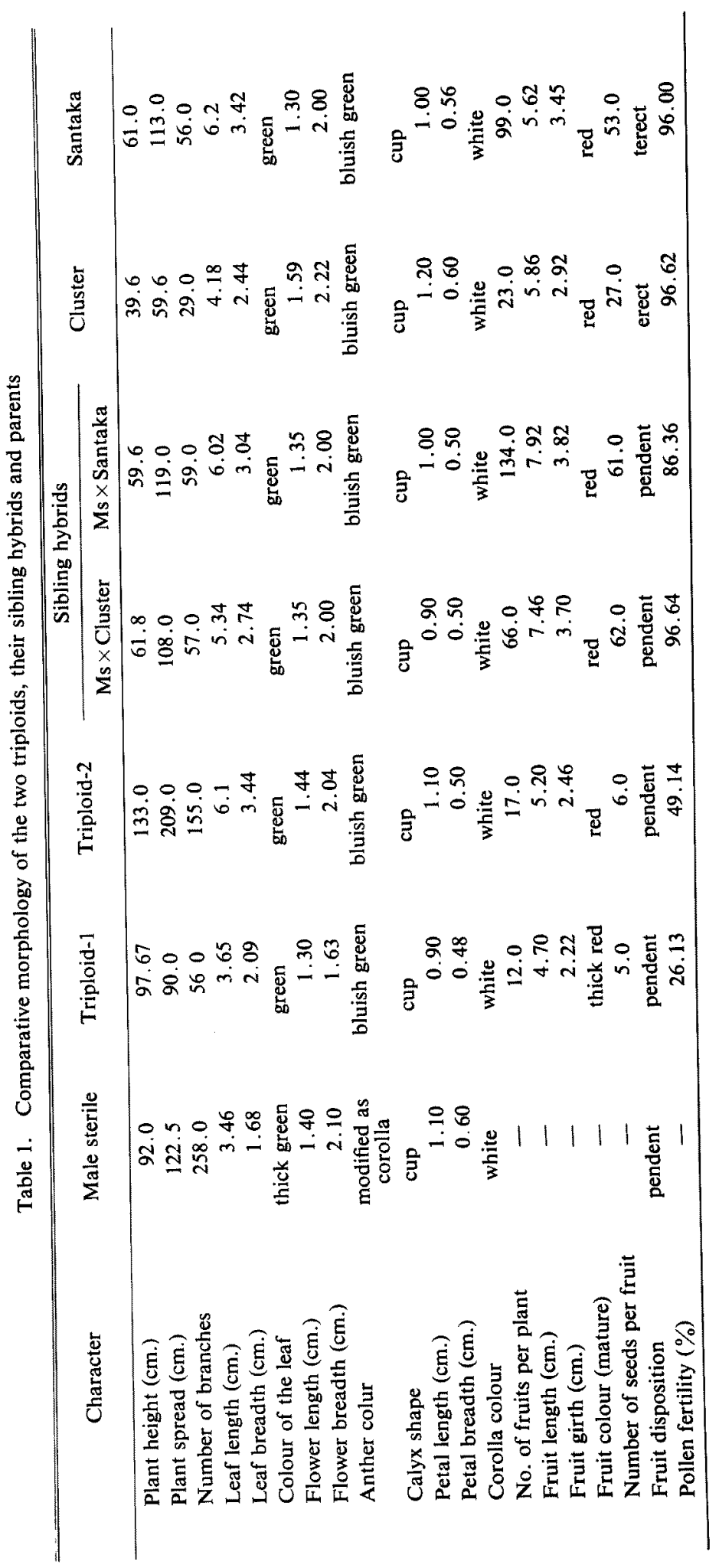


formation of as many as 4-8 nuclei and 1-10 micronuclei in Triploid-1 and 5-10 nuclei and 1-6 micronuclei in Triploid-2 (Figs. 7, 8).

\section{Discussion}

The occurrence of triploids in the intervarietal hybrid progeny was hithrero unknown in the genus Capsicum. However, in the present investigation, two triploids were recorded for

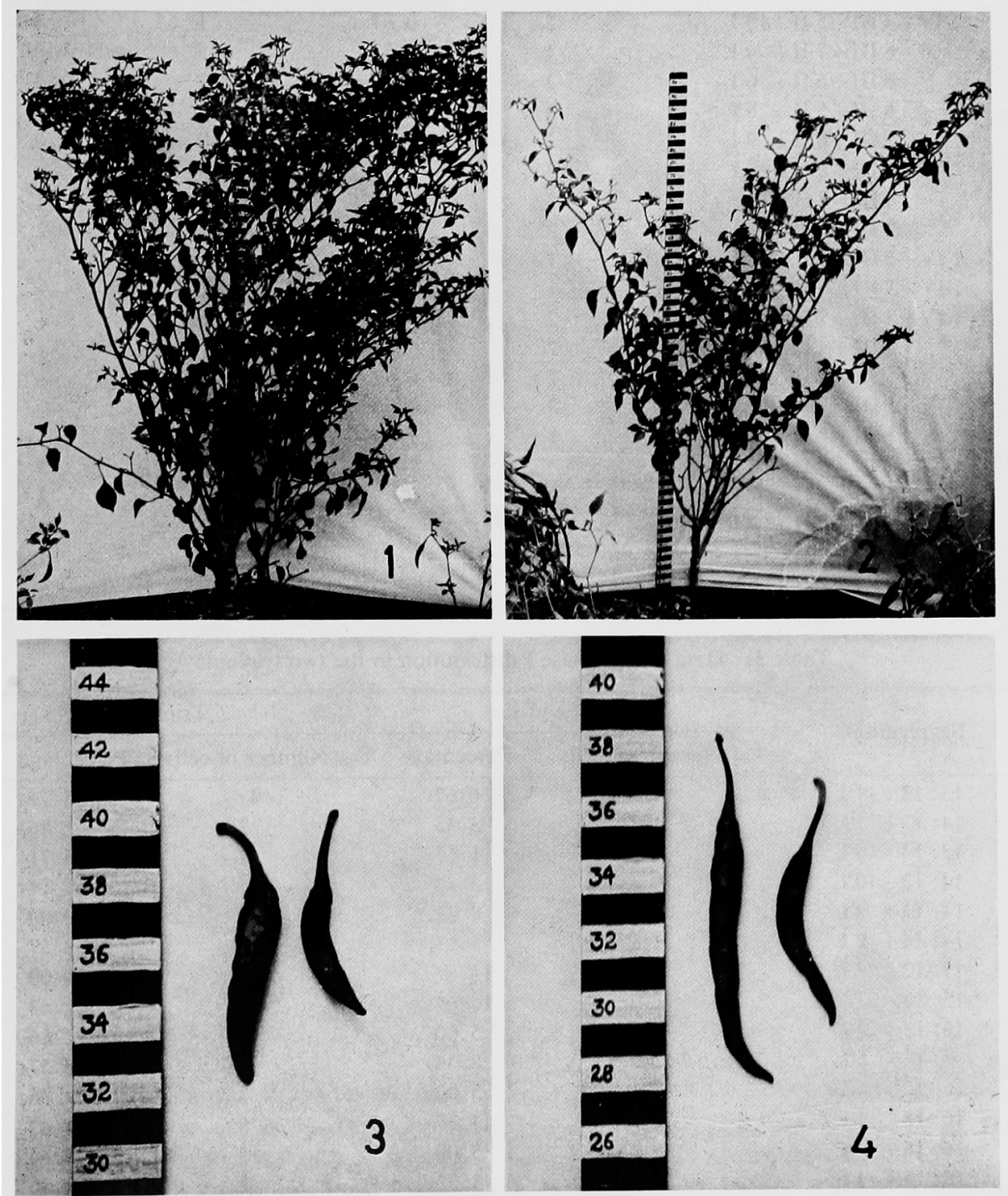

Figs. 1-4. Plant and fruit photographs of Triploid-1 and-2. 1, Triploid-2. 2, Triploid-1. 3, fruits of diploid hybrid and Triploid-2. 4, fruits of diploid hybrid and Triploid-1.

the first time in the progeny of the hybrids Ms $\times$ Cluster and Ms $\times$ Santaka. A feature of particular interest to note is that both the triploids were obtained in the hybrid progeny where the male sterile is the pistillate parent. Besides these two, three more triploids were screened by Nalini Kumari (1986) in our laboratory in the progeny of varietal crosses with the same 
male sterile line. These observations in conjunction with those of Nalini Kumari (1986) are suggestive of the production of viable unreduced gametes in the male sterile line employed.

Table 2. Chromosome associations in the two triploids at diakinesis

\begin{tabular}{|c|c|c|c|c|}
\hline \multirow{2}{*}{ Type of association } & \multicolumn{2}{|c|}{ Triploid-1 } & \multicolumn{2}{|c|}{ Triploid-2 } \\
\hline & $\begin{array}{l}\text { Number of } \\
\text { cells }\end{array}$ & Percentage & $\begin{array}{c}\text { Number of } \\
\text { cells }\end{array}$ & Percentage \\
\hline $1 I V+4 I I I+6 I I+8 I$ & 1 & 3.33 & 1 & 2 \\
\hline $1 I V+4 I I I+5 I I+10 I$ & 2 & 6.67 & 1 & 2 \\
\hline $6 \mathrm{III}+7 \mathrm{II}+4 \mathrm{I}$ & 1 & 333 & 5 & 10 \\
\hline $6 \mathrm{III}+6 \mathrm{II}+6 \mathrm{I}$ & 2 & 6.67 & 2 & 4 \\
\hline $6 \mathrm{III}+5 \mathrm{II}+8 \mathrm{I}$ & 2 & 667 & 8 & 16 \\
\hline $5 \mathrm{III}+6 \mathrm{II}+9 \mathrm{I}$ & 2 & 6.67 & 10 & 20 \\
\hline $4 I I I+8 I I+8 I$ & 3 & 10.00 & 3 & 6 \\
\hline $4 \mathrm{III}+7 \mathrm{II}+10 \mathrm{I}$ & 3 & 10.00 & 6 & 12 \\
\hline $3 \mathrm{III}+8 \mathrm{II}+11 \mathrm{I}$ & 2 & 6.67 & 1 & 2 \\
\hline $1 I V+5 I I I+5 I I+7 I$ & 1 & 333 & - & - \\
\hline $1 I V+5 I I I+4 I I+9 I$ & 1 & 3.33 & - & - \\
\hline $1 I V+3 I I I+7 I I+9 I$ & 2 & 6.67 & - & - \\
\hline $5 I I I+9 I I+3 I$ & 2 & 667 & - & - \\
\hline $5 \mathrm{III}+8 \mathrm{II}+5 \mathrm{I}$ & 2 & 6.67 & - & - \\
\hline $5 \mathrm{III}+7 \mathrm{II}+7 \mathrm{I}$ & 3 & 10.00 & - & - \\
\hline $3 \mathrm{III}+7 \mathrm{II}+13 \mathrm{I}$ & 1 & 3.33 & - & - \\
\hline $1 \mathrm{VI}+1 \mathrm{IV}+4 \mathrm{III}+5 \mathrm{II}+4 \mathrm{I}$ & - & - & 1 & 2 \\
\hline $7 \mathrm{III}+4 \mathrm{II}+7 \mathrm{I}$ & - & - & 1 & 2 \\
\hline $5 \mathrm{III}+7 \mathrm{II}+7 \mathrm{I}$ & - & - & 7 & 14 \\
\hline $5 \mathrm{III}+5 \mathrm{II}+11 \mathrm{I}$ & - & - & 2 & 4 \\
\hline $4 I I I+9 I I+6 I$ & - & - & 2 & 4 \\
\hline
\end{tabular}

Table 3, Data on anaphase I distribution in the two triploids

\begin{tabular}{lccccc}
\hline \multirow{2}{*}{ Segregation } & \multicolumn{2}{c}{ Tirploid-1 } & & \multicolumn{2}{c}{ Triploid-2 } \\
\cline { 2 - 3 } \cline { 5 - 6 } & Number of cells & Percentage & & Number of cells & Percentage \\
\hline $13: 12+11 \mathrm{~L}$ & 4 & 6.67 & & 4 & 5.71 \\
$14: 11+11 \mathrm{~L}$ & 2 & 3.33 & & 2 & 2.86 \\
$13: 13+10 \mathrm{~L}$ & 1 & 1.67 & & 4 & 5.71 \\
$14: 12+10 \mathrm{~L}$ & 2 & 33 & & 5 & 7.14 \\
$14: 13+9 \mathrm{~L}$ & 5 & 8.33 & & 7 & 10.00 \\
$14: 14+8 \mathrm{~L}$ & 5 & 8.33 & & 6 & 8.57 \\
$15: 13+8 \mathrm{~L}$ & 7 & 11.67 & & 7 & 10.00 \\
$15: 14+7 \mathrm{~L}$ & 10 & 16.67 & & 8 & 11.43 \\
$16: 13+7 \mathrm{~L}$ & 3 & 5.00 & & 2 & 2.86 \\
$16: 14+6 \mathrm{~L}$ & 5 & 8.34 & & 6 & 8.57 \\
$15: 15+6 \mathrm{~L}$ & 3 & 5.00 & & 2 & 2.86 \\
$16: 15+5 \mathrm{~L}$ & 7 & 11.67 & & 8 & 11.43 \\
$16: 16+4 \mathrm{~L}$ & 3 & 500 & & 5 & 7.14 \\
$17: 15+4 \mathrm{~L}$ & 2 & 3.33 & & 2 & 2.86 \\
$17: 16+3 \mathrm{~L}$ & 1 & 1.67 & & 1 & 1.43 \\
$17: 17+2 \mathrm{~L}$ & - & - & 1 & 1.43 \\
\hline
\end{tabular}

$\mathrm{L}=$ Laggards

Triploids generally arise by crossing tetraploids with diploids or due to fertilization of a haploid egg by two male gametes. They may also originate as an offspring from diploid parents by the union of an unreduced diploid gamete with a normal gamete. In the present case, the 
unreduced gamete might have been contributed by the pistillate male sterile parent and its subsequent fusion with a normal male gamete could have resulted in triploidy.

Polyploids generally exhibit enhanced size in different characters such as height, cell size, stomata etc, but here only plant height has been increased while there was reduction in the number of fruits per plant, number of seeds per fruit and pollen fertility. Thus triploidy does not seem to be the optimum level of ploidy in Capsicum.

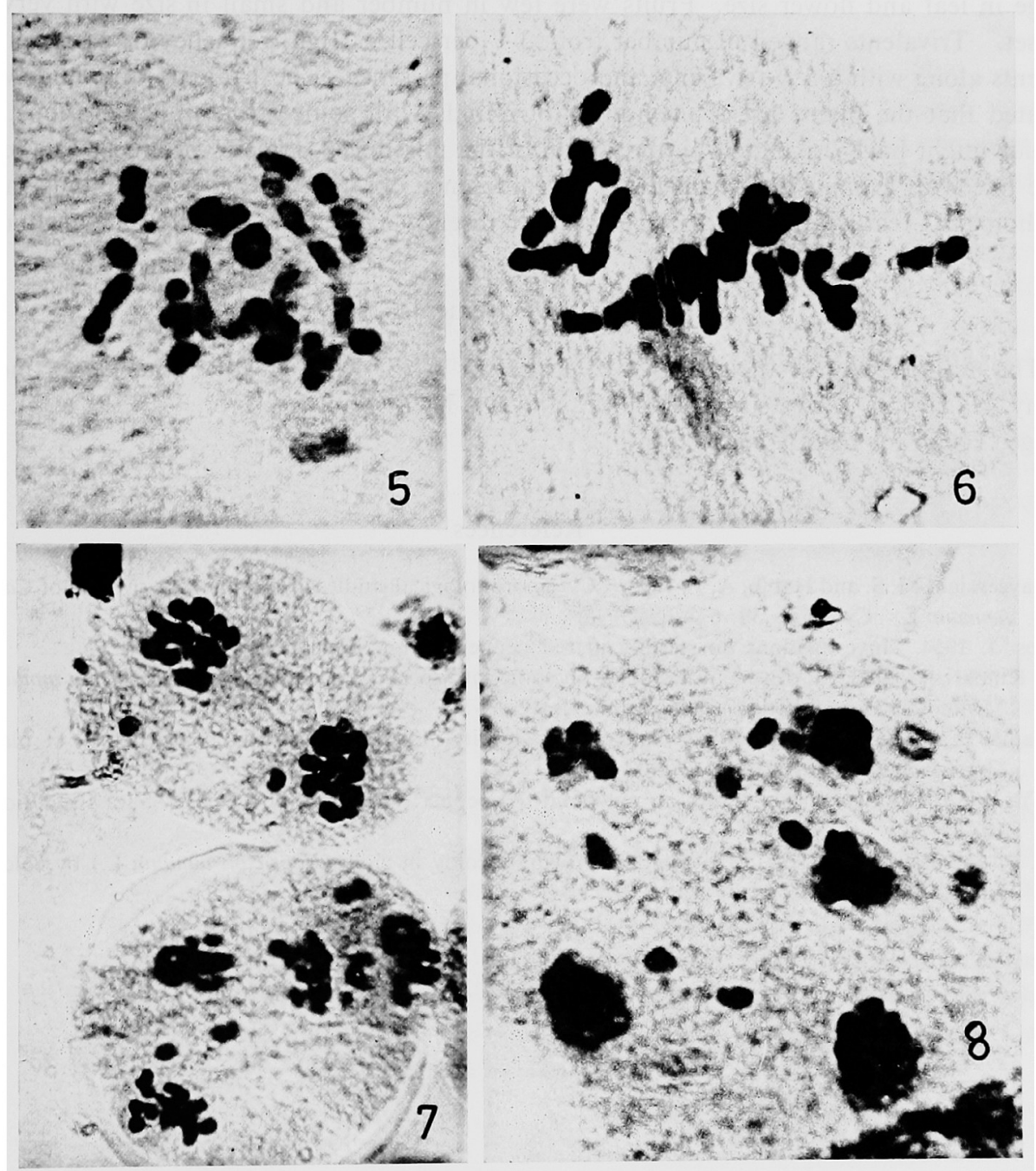

Figs. 5-8. Meiotic stages in Triploid-1 and 2, 5, Triploid-2, diakinesis with 1 VI +1 IV +2 III + $10 \mathrm{II}, \times 2400,6$. Triploid-2, metaphase-I showing stickiness of chromosomes, $\times 2500,7$, telophase I and II cells with 3 and 5 micronuclei respectively in Triploid-1. $\times 2200.8$, telophase

II showing 5 nuclei and several micronuclei in Triploid-1. $\times 2750$.

Because of the presence of large number of univalents and less number of trivalents encountered, the triploids can be considered as segmental autotriploids. The differences observed in the cytomorphology were due to the absence of uniform genetic background, which is evideneced by the involvement of two different male parents in the origin of the two triploids. The occurrence of higher assocations such as hexavalents and quadrivalents is indicative of the 
presence of structural alterations. The triploids will serve as a good source of aneuploids which are of immense value in genetic experiments.

\section{Summary}

Two autotriploids were isolated in the $F_{1}$ hybrid progeny of Ms $\times$ Cluster and Ms $\times$ Santaka. Triploids exhibited increased vigour in plant height and spread with no marked change in leaf and flower size. Fruits were few in number and small in size with very poor seed set. Trivalents ranged in number from 3-7 per cell. High frequency of univalents and bivalents along with a few trivalents and occasional presence of hexavalents and qudrivalents indicated that the plants are segmental autotriploids with some structural alterations. The triploids might have originated by the fusion of the unreduced gametes produced in the male sterile line with normal male gametes. The difference observed in the two triploids in cytomorphological features can be ascribed to the absence of uniform genetic background.

\section{Acknowledgements}

The authors express their thanks to Professor A. S. Rao, Head of the Department of Botany, Nagarjuna University for facilities and Dr. N. B. Rao, Lecturer, V. S. R. \& N. V. R. College, Tenali for helpful suggestions.

\section{References}

Chennaveeraiah, M. S. and Habib, A. F. 1973, Cytomorphological studies in spontaneous triploid of Capsicum annuum L. Cytologia 38: 677-685.

Kormos, J. 1954. Investigations on sterility in red pepper. Ann. Biol. Tihany 22: 235-252.

Nalini Kumari, P. 1986. Cytogenetical studies on some intraspecific hybrids of chilli (Capsicum annuum L.). M. Phil. Thesis submitted to Nagarjuna University.

Nishiyama, 1. and Karasawa, H. 1954. Somaplastic sterility in reciprocal crosses between $2 x \times 4 x$ plants in Capsicum. Jap. J. Breed. 3: 36-40.

Ohta, Y. 1962. Cytogenetical studies on polyploid red pepper. Seiken Zhiho Rep. Kihara Inst. Biol. Res. 13: 89-92.

Pal, B. P. and Ramanujam, S. 1939. Induction of polyploidy in chilli (Capsicum annuum L.) by colchicine. Nature $143: 245-246$. 